\title{
Review
}

Neuro

epidemiology

\section{The Prevalence, Impact and Economic Implications of Atrial Fibrillation in Stroke: What Progress Has Been Made?}

\author{
Nadine E. Andrew ${ }^{\mathrm{a}}$ Amanda G. Thrift ${ }^{\mathrm{a}, \mathrm{b}}$ Dominique A. Cadilhac ${ }^{\mathrm{a}-\mathrm{c}}$ \\ a Stroke and Ageing Research Centre, Department of Medicine, Monash Medical Centre, Southern Clinical School,

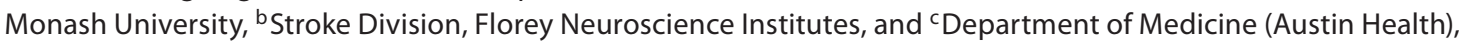 \\ The University of Melbourne, Melbourne, Vic., Australia
}

\section{Key Words}

Atrial fibrillation $\cdot$ Stroke $\cdot$ Prevalence $\cdot$ Risk $\cdot$ Economic evaluation

\begin{abstract}
Atrial fibrillation (AF) is a major risk factor for stroke, especially in the elderly. Increased life expectancies mean that AF-related stroke is a growing global public health concern. Improvements in the detection, treatment and prevention of the consequences of AF have occurred in recent years. However, the extent to which these improvements have impacted on the prevalence of AF, the risk of AF-related stroke and subsequent economic costs are unknown. This review provides a contemporary assessment of the epidemiological data on AF-related stroke aimed at assessing the effectiveness of primary prevention strategies and associated economic implications with reductions in stroke incidence. A systematic review of the literature was performed. Appropriately designed studies were identified and retrieved. Evidence on changes in the prevalence of $A F$, the risk of stroke associated with AF and the excess cost of AF-related stroke over the last 30 years was summarised. The results provide evidence that the age-adjusted prevalence of AF and the relative risk of stroke associated with AF has remained relative-
\end{abstract}

ly constant. Unless action is taken to improve detection of AF and reduce its consequences, a considerable increase in the social and economic burden associated with AF-related stroke is likely.

Copyright $\odot 2013$ S. Karger AG, Basel

\section{Introduction}

Atrial fibrillation (AF) is the most common of cardiac arrhythmias and is well recognised as a major risk factor for ischaemic stroke and transient ischaemic attacks. Approximately $15-20 \%$ of patients experiencing ischaemic stroke have AF [1-3]. Stroke severity and in-hospital mortality are also significantly greater in those with AF $[1,2$, 4]. AF occurs most commonly in older populations. Therefore, the increased life expectancy in both developed and developing countries means that AF-related stroke has become a growing global public health concern. The associated costs of treating the consequences of AF potentially place a significant economic burden on health systems and society.

The increased recognition of AF as a major contributor to the burden of stroke has led to advances in the detection and treatment of AF and the development of strat-

\section{KARGER}

E-Mail karger@karger.com

www.karger.com/ned
(C) 2013 S. Karger AG, Basel

0251-5350/13/0404-0227\$38.00/0
Prof. Amanda Thrift

Head, Epidemiology and Prevention Unit, Stroke and Ageing Research Centre (STARC) Department of Medicine, Monash Medical Centre, Southern Clinical School Monash University, Level 1/43-51 Kanooka Grove, Clayton, VIC 3168 (Australia) E-Mail amanda.thrift@monash.edu 
egies to prevent AF-related stroke. The extent to which these advances in recent years have impacted on the prevalence of AF, the risk of stroke and the economic impact of AF-related stroke has not been explored.

Because of differences in the types, presentations and diagnoses of AF, epidemiological data reported in the literature vary according to the location of the study population and the method of diagnosis [5]. There are three main types of AF reported in the literature: paroxysmal or intermittent AF, which involves intermittent episodes that resolve spontaneously within a week; persistent AF, which can be reversed through surgical or pharmacological intervention, and permanent $\mathrm{AF}$, in which the arrhythmia is constant but not reversible. Atrial flutter is considered to be a milder form of AF and is also associated with an increased risk of stroke [6].

Many AF sufferers experience no symptoms; between 24 and $50 \%$ of cases are reported as undiagnosed [7]. Asymptomatic AF is also more common in those with permanent $\mathrm{AF}$ than in those with intermittent $\operatorname{AF}[8,9]$. Consequently, AF is often not diagnosed until patients present to hospital with stroke, or it is incidentally diagnosed during routine electrocardiogram (ECG) examinations. This is concerning since asymptomatic AF affords the same stroke risk as symptomatic AF [10] and, if left undiagnosed, may provide additional risks associated with the lack of access to preventive treatments.

Diagnosis of intermittent AF may also be complicated by the fact that it may not be identified by a single ECG reading. Continuous ECG monitoring for periods of 24 $\mathrm{h}$ or more in stroke patients can approximately double the number of AF cases diagnosed when compared to a single short ECG reading [11, 12]. Nevertheless, gaining an understanding of the prevalence of $\mathrm{AF}$ and associated trends is important for estimating the proportion of the population that are at increased risk of stroke attributable to AF.

Quantifying the risk of stroke independently associated with AF can also be problematic. Increases in the number of AF patients with additional risk factors for stroke, such as cardiovascular disease or increased age, will increase the overall relative risk of AF-related stroke. However, improved treatment options for the management of AF and prevention of stroke have the potential to reduce the number of strokes associated with AF $[13,14]$. Furthermore, improvements in knowledge about the AFrelated stroke risk and treatment options may encourage both doctor prescription of anti-thrombotic medications and patient compliance. This is important, as stroke prophylaxis with anticoagulants has been reported as sub- optimal [15]. Attenuation of the consequences of stroke, with improvements in care and treatment, may also impact on AF-related stroke and related costs. The extent to which these factors have impacted on AF-related stroke remains unclear.

A contemporary assessment of the epidemiological data is required to assess the effectiveness of primary prevention strategies and any associated economic implications with reductions in stroke incidence observed over the last 30 years. Summarising the current literature on the proportion of the total cost burden that can be attributed to AF-related stroke and any changes in the magnitude of these costs over time is an important part of monitoring the effectiveness of current preventive strategies. Therefore, the aims of this review were to (1) describe the prevalence of $\mathrm{AF}$ and how this may have changed over time, (2) provide contemporary estimates of the risk of stroke associated with AF and how this may have changed over time and (3) describe the excess costs of AF-related stroke compared with non-AF-related stroke and how this may have changed over time.

\section{Methods}

The methods used are based on those recommended in the international literature. In 2008, the National Heart, Lung, and Blood Institute convened an expert panel to identify gaps in the current research knowledge base for AF and make recommendations for future research strategies [16]. Two of their recommendations specific to this literature review were the following: (1) that systematic longitudinal large appropriately designed cohort studies be used to define trends and risk factors associated with AF, and (2) that longitudinal natural history studies be used to define the clinical course of AF.

Based on these recommendations, we included only large population-based cohort studies in this review. To allow comparability between studies over time, specific methodological criteria were established for each of the aims (see Search Strategy below). Studies meeting these criteria were included in the final analyses. The inclusion criteria for each of the aims are outlined in table 1.

Types of Participants

Adult populations ( $\geq 18$ years of age) diagnosed with any type of AF or atrial flutter.

\section{Diagnosis of $A F$}

The diagnostic criteria differed according to each of the review questions. To examine the prevalence of AF, we included only studies in which all participants underwent routine ECG at baseline. This provided consistent diagnostic criteria and ensured capture of both symptomatic and asymptomatic AF cases. Cohort studies that were designed to exclude those with pre-existing medical conditions or relied solely on hospital, medical or health insurance company databases were excluded for the prevalence 
Table 1. Selection criteria for studies included in the review

\begin{tabular}{lll}
\hline Prevalence studies & Stroke risk studies & Cost analysis studies \\
\hline $\begin{array}{l}\text { Population cohort studies or } \\
\text { cross-sectional surveys }\end{array}$ & Cohort or case-control studies & Cohort or case-control studies \\
\hline AF confirmed by ECG at baseline & AF confirmed by ECG or medical records & AF confirmed by ECG or medical records \\
\hline Recruitment rate $\geq 60 \%$ & NA & NA \\
\hline All forms of AF & All forms of AF & All forms of AF \\
\hline $\begin{array}{l}\text { Participants not excluded on } \\
\text { the basis of medical history }\end{array}$ & Stroke diagnosed via ICD-10 or & Stroke diagnosed via ICD-10 or \\
\hline & ICD-9 codes or brain imaging & ICD-9 codes or brain imaging \\
\hline & All strokes & All strokes \\
\cline { 2 - 3 } & Relative risks reported & $\begin{array}{l}\text { Cost data presented separately for patients } \\
\text { with and without AF }\end{array}$ \\
\cline { 2 - 3 }
\end{tabular}

ICD-10 = International Classification of Diseases, 10th edition; ICD-9 = International Classification of Diseases, 9th edition; NA = not applicable.

analysis, because of the potential for selection or misclassification bias. Similarly, for the review of prevalence, we excluded studies where less than $60 \%$ [17] of the eligible population were recruited, in order to reduce the impact of selection bias in our comparisons. For the review of stroke risk and costs, we included studies where AF could be confirmed by ECG and/or identified from medical records. Those in which the presence of AF was obtained through patient self-report were excluded. All forms of AF were included, since many investigators did not differentiate between the type or cause of AF.

\section{Outcome}

The primary outcome of interest was all stroke types, including transient ischaemic attacks. AF is most commonly associated with the occurrence of ischaemic stroke, but not all investigators differentiated between stroke types. Because ischaemic stroke accounts for approximately $80 \%$ of all stroke [18], studies in which all strokes were included therefore predominantly comprise ischaemic strokes. We included both fatal and non-fatal strokes and only included studies in which stroke was confirmed on the basis of International Classification of Diseases, 9th or 10th edition coding and/or brain imaging. When establishing the risk of stroke associated with AF, we included only studies with relative risks produced using multivariable analysis, whereby well-known stroke risk factors such as age, gender and hypertension were adjusted for in the estimation.

\section{Search Strategy}

A separate search strategy was used for each of the review aims, as follows:

(1) To establish the prevalence of AF, MEDLINE and EMBASE were searched using the following terms: (AF or atrial fibrillation).tw. and (prevalen\$ or epidemiolog\$).tw. and (cohort or 'case control' or 'cross sectional' or survey or 'population based').

Prevalence, Impact and Economic Implications of AF in Stroke
(2) To establish the risk of stroke associated with AF, MEDLINE and EMBASE were searched using the following terms: (AF or atrial fibrillation).tw. and (cohort or 'case control' or 'cross sectional' or survey or 'population based').tw. and (stroke or CVA or cerebrovascular\$).tw. and risk.tw.

(3) To establish the excess cost of AF-related stroke, MEDLINE, EMBASE and Ecolit were searched using the following terms: (AF or atrial fibrillation).tw. and (cohort or 'case control' or 'cross sectional' or survey or 'population based').tw. and (cost\$ or economic\$).tw.

Searches were limited to English-language citations, from January 1950 to September 2011. Grey literature, in the form of reports, was searched, and the reference lists of key articles from the searches were checked for additional relevant studies.

\section{Data Collection and Management}

Study identification and data extraction were performed by the first author (N.E.A.) based on the titles and abstracts of articles identified by the search strategy. For those abstracts that appeared to meet the review criteria, full-text articles were retrieved and assessed. Final selection of eligible studies and uncertainty over eligibility was resolved by consensus from the three review authors.

The methodological quality of the identified studies was assessed with reference to the Strengthening the Reporting of Observational Studies in Epidemiology statement [19]. Criteria derived from this statement that were used to assess the quality of studies were: detailed eligibility criteria; well-described sources and methods of selection of participants; well-described diagnostic criteria and method of diagnosis; reporting of potential sources of bias; reporting of the numbers of individuals at each stage of study, e.g. number eligible, number recruited, number analysed; description of the characteristics of the study population, and appropriate reporting of results. Additional criteria were applied to studies in which the risk of stroke associated with 


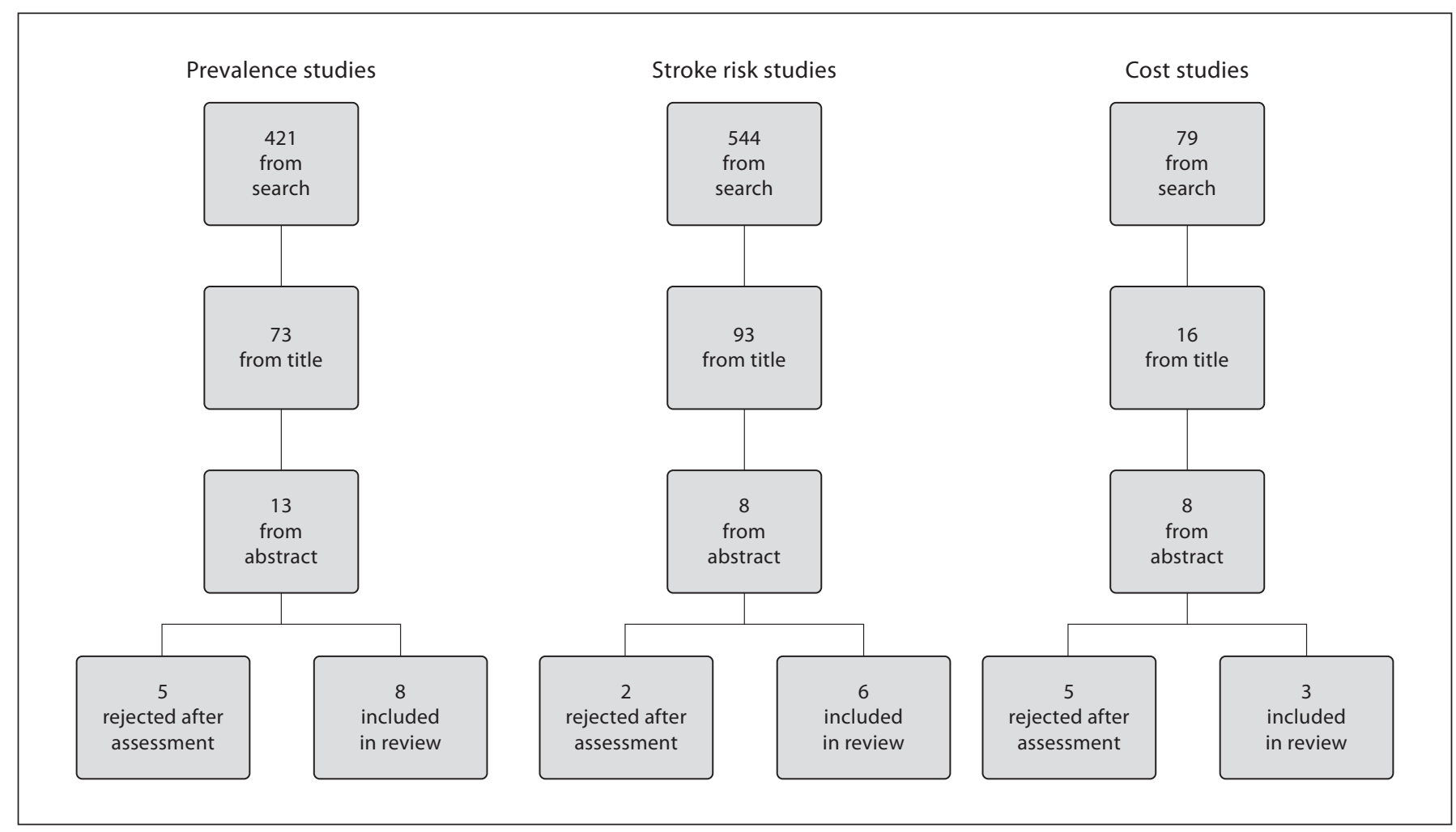

Fig. 1. Summary of results from the three search strategies.

AF was reported. These were: clearly defined outcome definitions; an explanation of how loss to follow-up was addressed; reporting of the number of outcome events, and the extent to which relevant confounding factors were included in adjusted relative risk estimations.

\section{Data Analysis}

Because the prevalence of AF may vary between age groups, gender groups and ethnic groups [20,21], results pertaining to the prevalence of AF were sub-categorised according to these factors. Where possible, prevalence rates were age adjusted and confidence intervals (CIs) were calculated to enable comparison between studies over time. Age categorisation varied greatly between studies. To promote comparability between studies, age-adjusted prevalence rates are reported for those aged $\geq 65$ years.

The relative risk of stroke was compared between studies. Where possible, a meta-analysis of the combined results from comparable studies was performed to provide an overall assessment of the relative risk of stroke associated with AF. A test for heterogeneity was performed to assess whether there was variation in the true effects underlying the studies. A p value $>0.2$ was used as a cut-off for homogeneity of the risk of stroke associated with AF. Where possible, the absolute risk of stroke associated with AF was also calculated.

\section{Results}

Figure 1 provides an overview of the results for each search strategy used and the final number of articles that were used to address each review aim.

\section{Prevalence}

In total, 421 articles were identified using the search strategy. Of these, 73 were identified as eligible following review of the title. This was reduced to 13 studies following review of the abstracts [22-34]. Following methodological assessment of the quality of the full articles, 3 studies were excluded since they did not meet the inclusion criteria $[22,24,30]$, and a further 2 studies were excluded because of low response rates $[29,33]$. This left 8 studies for inclusion in the review of changes to the prevalence of AF (fig. 1). These studies are summarised in table 2 .

All included studies were part of large populationbased cohort studies. Four were based in Europe, 3 in Asia and 1 in Australia. All forms of AF were included in the studies. Heeringa et al. [25] and Zhou and $\mathrm{Hu}$ [34] 
Table 2. Characteristics of the AF prevalence studies included in the review

\begin{tabular}{|c|c|c|c|c|c|c|c|c|c|c|}
\hline Study & Year & Location & Setting & Study design & $\begin{array}{l}\text { Assessment } \\
\text { method }^{1}\end{array}$ & $\begin{array}{l}\text { Diagnostic } \\
\text { criteria }\end{array}$ & $\begin{array}{l}\text { Person making } \\
\text { assessment }\end{array}$ & $\begin{array}{l}\text { Eligible } \\
\text { patients } \\
\text { included }^{2} \\
\%\end{array}$ & $\begin{array}{l}\text { Percentage } \\
\text { of total } \\
2 \text { analysed }\end{array}$ & $\begin{array}{l}\text { Total } \\
\mathrm{n}\end{array}$ \\
\hline $\begin{array}{l}\text { Lake et al. } \\
\text { [23] }\end{array}$ & $1966-1983$ & Australia & $\begin{array}{l}\text { Busselton } \\
\text { community }\end{array}$ & $\begin{array}{l}\text { prospective } \\
\text { cohort (whole } \\
\text { community) }\end{array}$ & $\begin{array}{l}\text { 12-lead resting } \\
\text { ECG }\end{array}$ & $\begin{array}{l}\text { Minnesota } \\
\text { code }\end{array}$ & not reported & $64-94$ & & 1,770 \\
\hline $\begin{array}{l}\text { Chien et al. } \\
\text { [26] }\end{array}$ & $1992-2000$ & Taiwan & $\begin{array}{l}\text { Chin-Shan } \\
\text { township }\end{array}$ & $\begin{array}{l}\text { prospective } \\
\text { cohort (whole } \\
\text { community) }\end{array}$ & ECG & well defined & cardiologist & 83 & 99 & 3,560 \\
\hline $\begin{array}{l}\text { Bilato et al. } \\
\text { [27] }\end{array}$ & $\begin{array}{l}1995-1998 \\
(\mathrm{BL}) \\
6 \text {-year FU }\end{array}$ & Italy & $\begin{array}{l}2 \text { towns in } \\
\text { north-east } \\
\text { Italy }\end{array}$ & $\begin{array}{l}\text { prospective } \\
\text { cohort (ran- } \\
\text { dom sample) }\end{array}$ & ECG & not reported & cardiologist & 90 & 99 & 1,576 \\
\hline $\begin{array}{l}\text { Yap et al. } \\
{[32]}\end{array}$ & 2004-2005 & Singapore & Singapore & $\begin{array}{l}\text { whole area } \\
\text { survey }\end{array}$ & $\begin{array}{l}\text { 12-lead resting } \\
\text { ECG }\end{array}$ & & cardiologist & 85 & & 1,839 \\
\hline $\begin{array}{l}\text { Schmutz } \\
\text { et al. [31] }\end{array}$ & $2005-2007$ & Switzerland & Geneva & $\begin{array}{l}\text { whole area } \\
\text { survey - stratified } \\
\text { and random }\end{array}$ & $\mathrm{d}^{\text {6-lead ECG }}$ & well defined & cardiologist & 73 & & 3,285 \\
\hline $\begin{array}{l}\text { Zhou and } \\
\mathrm{Hu}[34]\end{array}$ & $\begin{array}{l}\text { not } \\
\text { reported }\end{array}$ & China & $\begin{array}{l}13 \\
\text { provinces }\end{array}$ & $\begin{array}{l}\text { prospective } \\
\text { cohort (cluster } \\
\text { random } \\
\text { sample) }\end{array}$ & $\begin{array}{l}\text { (1) resting ECG; } \\
\text { (2) medical } \\
\text { records; (3) prior } \\
\text { ECG }\end{array}$ & $\begin{array}{l}\text { American } \\
\text { College of } \\
\text { Cardiology } \\
\text { guidelines }\end{array}$ & $\begin{array}{l}\text { physician and } \\
\text { cardiologist }\end{array}$ & 96 & & 29,079 \\
\hline
\end{tabular}

included extra cases of intermittent AF by including patients diagnosed with AF based on general practitioner (GP) and hospital discharge records in addition to baseline ECG readings. Consequently, there was a slightly greater prevalence rate of $\mathrm{AF}$ in that study than in those where only ECG was used to diagnose cases. Between 41 and $72 \%$ of $\mathrm{AF}$ cases detected in these studies were asymptomatic $[28,31,32]$.

In all studies, there was a significant increase in the prevalence of AF with increasing age (table 3). This increase was consistent across gender and ethnic subgroups. Males had a slightly greater prevalence of AF compared to females. However, in some regions the gender difference was less apparent, as indicated by overlapping CIs (table 4) [23, 25, 34]. Age-adjusted prevalence rates for AF were lower in Asian populations than in Caucasian populations.

Prevalence, Impact and Economic Implications of AF in Stroke
There was no evidence for an increase in age-adjusted prevalence rates over time for the group as a whole or for the different sub-categories (table 4).

\section{Risk of Stroke Associated with AF}

A total of 544 articles were identified using the search strategy. Of these, 93 were identified as eligible following review of the title (fig. 1). Following review of the abstract, 8 studies were initially identified as eligible for inclusion, but 2 of these were subsequently excluded after assessment of the study methods. One of these was excluded because the relative risk of stroke-related AF was not reported [35] and the other because only univariable analyses were provided [36]. Of the 6 studies included in the final analysis, 5 were prospective cohort studies $[26,37-$ 40] and 1 was a case-control study [21]. In 5 studies, ECG was used to diagnose $\mathrm{AF}$, and so asymptomatic cases of 
Table 3. Unadjusted prevelence rates and $95 \%$ CIs by age groups

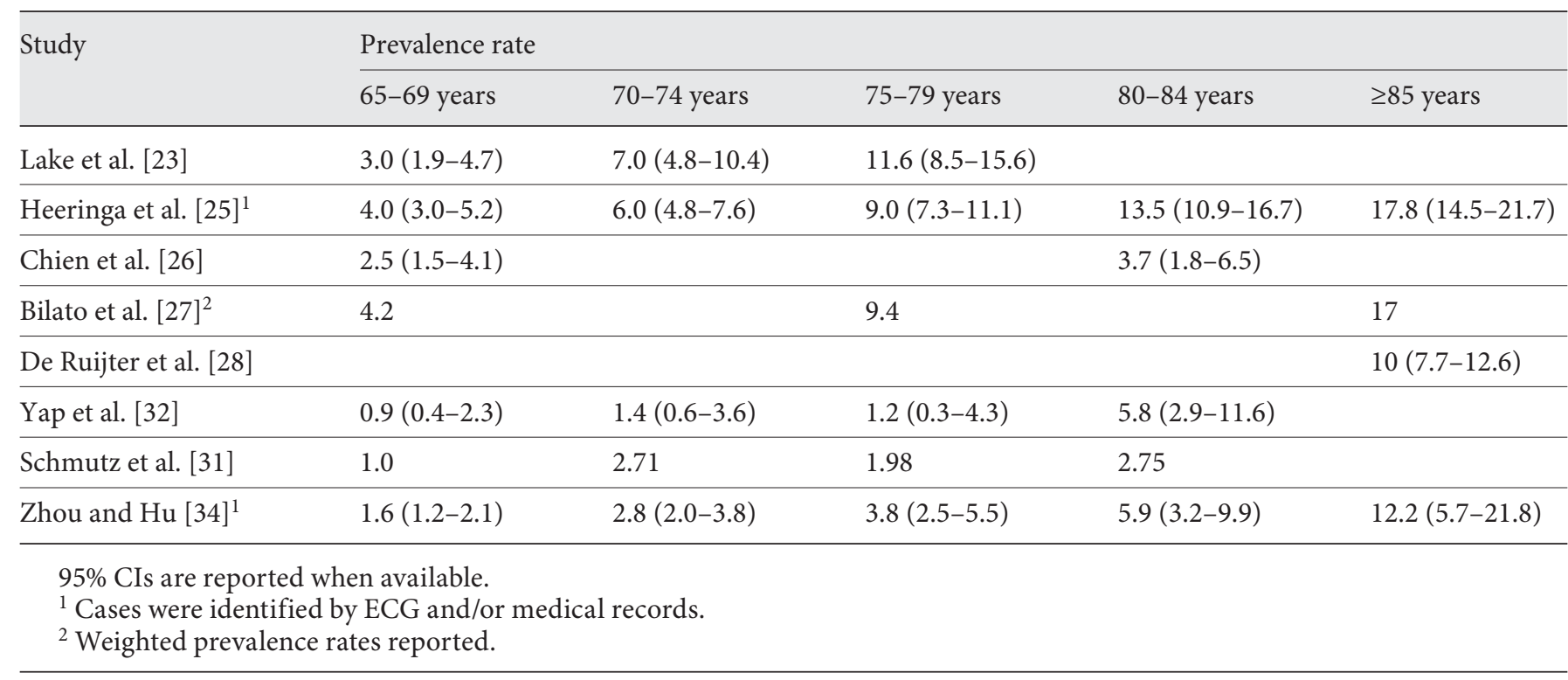

Table 4. Unadjusted and age-adjusted prevalence rates with $95 \%$ CIs by gender

\begin{tabular}{|c|c|c|c|c|c|c|c|}
\hline \multirow[t]{2}{*}{ Study } & \multirow[t]{2}{*}{ Year of study } & \multicolumn{2}{|c|}{ Males $\geq 65$ years } & \multicolumn{2}{|l|}{ Females $\geq 65$ years } & \multicolumn{2}{|c|}{ Total $\geq 65$ years } \\
\hline & & unadjusted & age adjusted & unadjusted & age adjusted & unadjusted & age adjusted \\
\hline Heeringa et al. $[25]^{2}$ & $1990-1993$ & $9.5(8.0-11.0)$ & $9.0(7.6-10.4)$ & $7.5(6.5-8.5)$ & $7.5(6.5-8.5)$ & $8.1(7.3-8.9)$ & $8.2(7.4-9.0)$ \\
\hline Chien et al. $[26]^{3}$ & $1992-2000$ & & & & & $2.8(1.7-3.9)$ & $2.9(1.9-4.2)$ \\
\hline Bilato et al. [27] & 1995-1998 & & $7.5(5.4-9.6)$ & & $7.3(5.7-9.0)$ & & $7.4(6.2-8.8)$ \\
\hline Zhou and $\mathrm{Hu}[34]^{2,3}$ & not reported & $2.9(2.3-3.5)$ & $2.8(2.2-3.4)$ & $2.1(1.5-2.7)$ & $2.1(1.5-2.7)$ & $2.5(2.1-2.9)$ & $2.5(2.1-2.9)$ \\
\hline $\begin{array}{l}{ }^{1} \text { Participants were } \\
{ }^{2} \text { Cases were ident } \\
{ }^{3} \text { These studies we } \\
{ }^{4} \text { Participants were }\end{array}$ & $\begin{array}{l}\text { aged }>60 \text { yea } \\
\text { ified by ECG a } \\
\text { re perfromed } \\
\text { aged } 70-85 \text { y }\end{array}$ & $\begin{array}{l}\text { /or medical r } \\
\text { Asian popula } \\
\text { rs, and only a }\end{array}$ & $\begin{array}{l}\text { cords. } \\
\text { ons. } \\
\text {-lead ECG wa }\end{array}$ & & & & \\
\hline
\end{tabular}

AF were included [26, 37-40]. In 1 study, GP records were used to identify AF cases [21]. Two studies were designed to exclude those patients with valvular or rheumatic $\mathrm{AF}$ $[21,37]$.

When comparing the results of the 6 included studies, no apparent differences in the adjusted relative risk of stroke between the studies were observed (table 5).

The adjusted relative risk of stroke associated with AF was generally consistent across studies and sub-groups. There was no apparent increase or decrease in adjusted relative risks over time between ethnic groups or for different age groups. The effect of gender on AF-related stroke risk was inconsistent. In one study, women had a greater adjusted relative risk of stroke than men [38], whereas in the other studies there were no differences between men and women [21, 39].

Sufficient data were provided for inclusion in the meta-analysis in 5 of the 6 studies to assess stroke risk associated with AF. In 3 studies, an overall relative risk was provided, and so these were combined to calculate an 


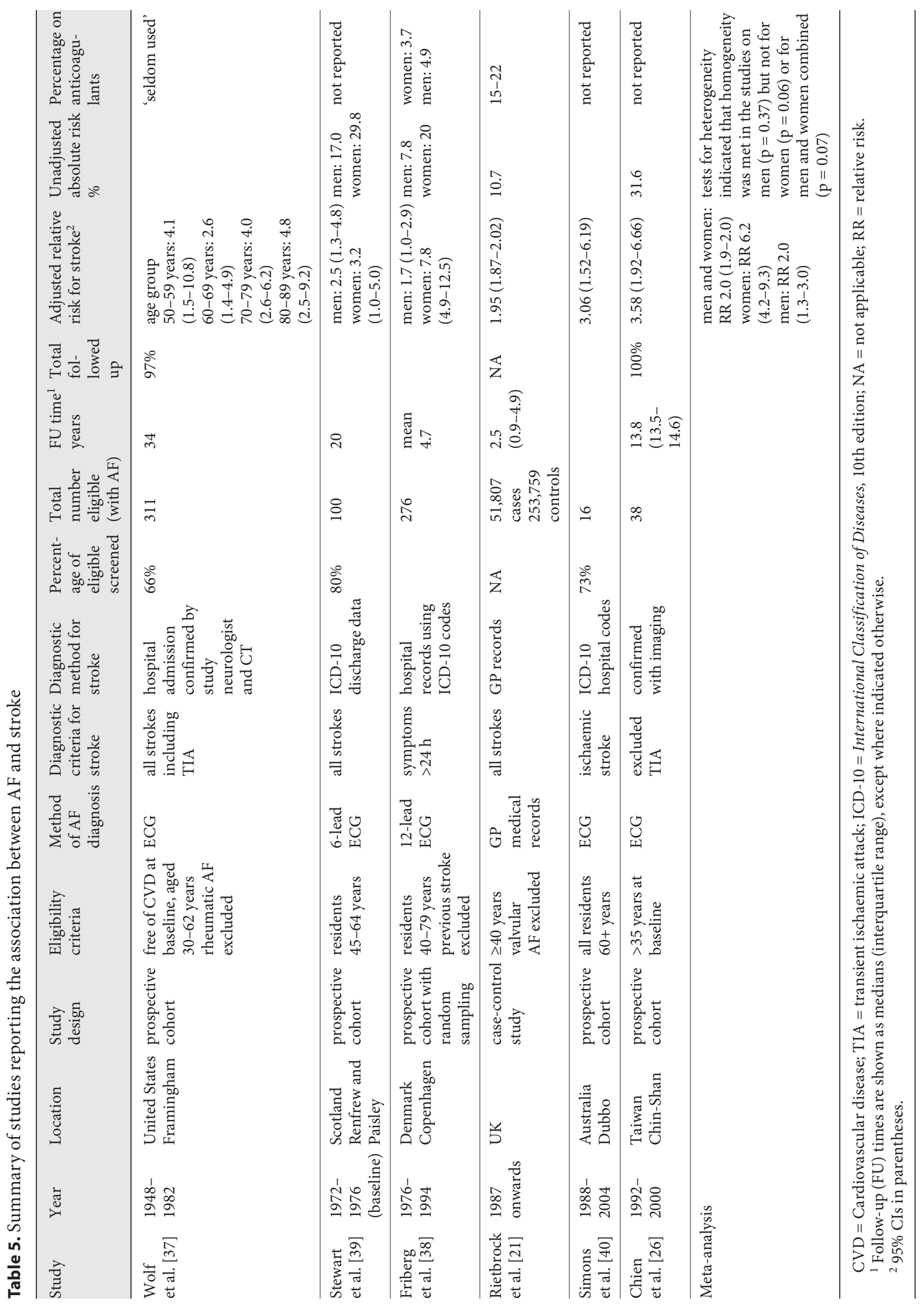


overall risk of stroke with AF $[21,26,40]$. In 2 of the studies, the adjusted relative risk of stroke was reported according to gender, and the results of these studies were combined to calculate the risk of stroke for men and women $[38,39]$. The overall excess risk of stroke associated with AF was 2.0 (95\% CI 1.9-2.0). In men alone, the excess risk of stroke associated with AF was 2.0 (95\% CI 1.3-3.0), while it was 6.2 (95\% CI 4.2-9.3) for women (table 5). In one study, the relative risk of stroke was reported by age group. This ranged from 2.6 in the 60 - to 69 -year-old age group to 4.5 in the 80 - to 89 -year-old age group [37].

The absolute risk of stroke associated with AF also varied between studies. This ranged from 7.8 to 31.6 [21, $26]$ and was generally higher for women [38, 39]. In the 3 studies in which the use of anticoagulant medication was reported, usage was low, ranging from 'seldom' to $27 \%$ $[21,37,38]$.

\section{Excess Costs of AF-Related Stroke}

We identified only 3 observational studies where authors specifically reported the excess cost of AF-related stroke compared with non-AF-related stroke [41-43]; 2 were retrospective cohort studies using registry data [42, 43], while the other was a prospective cohort study [41]. The retrospective cohort studies included over 1,000 stroke patients with AF, and only direct inpatient costs were included [42]. The prospective cohort study included 116 stroke patients with AF from four hospitals. This study was used to compare both the direct and indirect costs associated with AF-related stroke and non-AF-related stroke. A detailed description of each study is provided in table 6 .

In all studies, the direct costs of stroke were greater in patients with AF than in those without AF. However, this was reported as statistically significant in only 2 of the studies $[41,42]$. AF-related stroke cost an average of between 7 and 20\% more than non-AF-related stroke [4143]. The excess cost was primarily attributable to longer lengths of hospital stay, but also to a greater frequency of recurrent stroke events over a 3-year period [42]. Acute hospital costs remained greater for AF-related stroke when adjustment was made for potentially confounding variables such as gender, age and co-morbidities [41]. The excess costs associated with AF-related stroke were lower when fatal events were included in the analyses because of the higher mortality rate associated with AF-related stroke [42]. This may, in part, account for the lower excess costs reported by Meretoja et al. [43]. Multiple linear regression was used by authors in the Swedish study to demonstrate a significant association between $\mathrm{AF}$ and greater 3-year stroke costs [42]. There were too few studies to enable assessment of changes in AF-related stroke costs over time.

\section{Discussion}

We have found that the age-adjusted prevalence of AF appears to have remained relatively constant over the last 30 years. Large cohort studies have only been performed in Asian populations in the last 10 years, thereby making it difficult to identify time trends in this population. In contrast, a more accurate view of changes in prevalence was afforded for Caucasian populations, using data over a 30 -year period.

We further confirm that the prevalence of AF increases dramatically with age and tripled between the ages of 65-70 to 85 years and over. This increase was consistent across ethnic and gender groups. The increased prevalence of AF with age is concerning given that it is estimated that the proportion of the population aged $\geq 80$ years will increase globally from $1.3 \%$ in 2005 to $4.5 \%$ by 2050 [44]. In Europe, this proportion is projected to increase from 3.5 to $9.6 \%$, and in North America from 3.5 to $7.8 \%$ [44]. Even though the prevalence of AF in Asian populations is lower than in other populations, the projected population increase in this group is greatest. The proportion of the population over 80 years of age is projected to increase from 1 to $4.5 \%$ across Asia from 2005 to 2050 [44], with China estimating an increase from 1 to $6.5-$ $10.9 \%$ [45]. The extent to which the lower prevalence of AF in these countries is attributable to current lower life expectancies is unknown. These increases in life expectancy and lower fertility rates in most developed and developing countries are highly likely to lead to an increase in the prevalence of AF over this same time period [44]. Even in Asian countries, AF is likely to become a major contributor to the health and economic burden of chronic disease.

It has been hypothesised that increases in the survival of those with cardiovascular disease and stroke could result in an increase in the age-adjusted prevalence of AF [46]. An alternative hypothesis is that advances in medical treatments, such as ablations and primary rate or rhythm reversal interventions, and improved prevention strategies should, in theory, reduce the prevalence of AF. These two opposing factors may contribute to the lack of change in the prevalence of AF, despite advances in these areas. Studies of secular trends in the age-adjusted prevalence of AF, based on ECG diagnosis, provide variable results. In one study, AF prevalence in men rose over an 


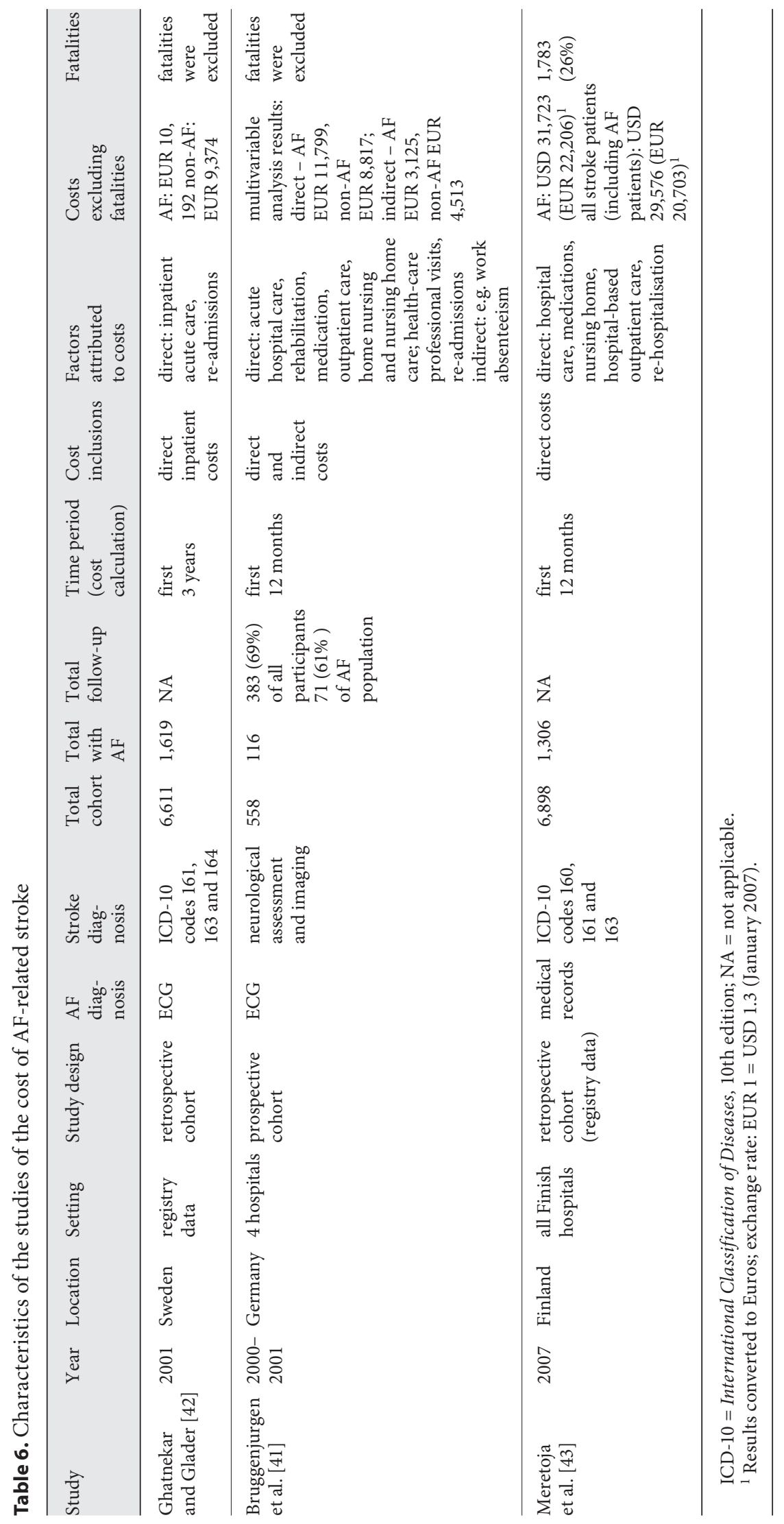


18-year period [47]. However, declining response rates over time may have resulted in biased estimates in that study [47]. Similar increases over time were found in studies in which AF was diagnosed by a GP or in hospital. This increase over time may be an artefact resulting from the increased availability of ECG and increased awareness and diagnosis of AF $[15,48]$. In contrast, Wolf et al. [49] found that there was no significant change in the prevalence of ECG-defined AF over time. Thus, there is some inconsistency between studies on whether or not there has been a change in the prevalence of AF over time.

Our finding of a lack of change in age-adjusted prevalence rates over time may also be due, in part, to the fact that the studies we captured included both symptomatic and asymptomatic cases of AF. The large number of asymptomatic cases incidentally diagnosed makes it difficult to independently assess the impact of effective treatment or management of $\mathrm{AF}$ and the prevention of the consequences of $\mathrm{AF}$ at a population level.

AF-related strokes are often more severe [50]. Early detection can allow preventive treatments to be implemented that reduce the risk of stroke as well as attenuate stroke severity. Prioritisation of care, such as stroke unit admission, for stroke patients with AF may also improve outcomes in this group. Further research is needed to investigate the impact of stroke prevention and management on reducing stroke severity and improving outcomes in AF-related stroke.

We found that there was a 2 - to 3.5 -fold increase in the risk of stroke among those with AF when compared to those without AF. This compares with a 4- to 5-fold increased risk that is often reported in the literature [51, 52]. This 4- to 5-fold increase is primarily based on the adjusted relative risks reported by Wolf et al. [37]. The authors of that study did not report an overall relative risk for their cohort, but instead reported results by age group. The relative risk ranged from 2.6 in the 60 - to 69 -year-old group to 4.5 in the 80 - to 89 -year-old group. When viewed within the context of the whole cohort, this is not dissimilar to our own results. The calculated relative risks reported in the literature will also be dependent upon the statistical analyses used and the type and number of other stroke risk factors accounted for in the multivariable analyses. Our inclusion of studies in which multivariable analyses had been undertaken may account for the lower relative risks reported in our review. In addition, many of the prospective studies in this review contained only small numbers of AF patients [26, 39, 40]. These studies had the advantage of reliable case definition through ECG diagnosis and included both symptomatic and asymptomatic AF. The lower relative risk reported in the only case-control study in this review may have resulted from misdiagnosis of $\mathrm{AF}$, as the patients were identified from medical records [21]. The large number of AF patients in that study would have skewed our meta-analysis results towards a slightly lower relative risk value.

The extent to which anticoagulant medication was used was not reported in many of the studies in this review $[26,39,40]$. Vitamin $\mathrm{K}$ antagonists or anticoagulant treatments such as warfarin can reduce the relative risk of stroke by as much as $64 \%[13,14]$, with aspirin or antiplatelet therapy having a lesser benefit of around 19\% [14]. Increased awareness of the mechanisms of AF-related stroke and advances in drug therapies should mean that later studies would include larger numbers of AF patients on these medications. The prescription of anticoagulant therapy such as warfarin in patients with $\mathrm{AF}$ increased in England between 1994 and 2003 from 25 to 53\% in men and from 21 to $41 \%$ in women, with over $80 \%$ of patients receiving some form of stroke prevention [15]. A recent study in Taiwan reported lower uses of stroke prevention medication of about $53 \%$, with only $11 \%$ of those admitted with stroke using warfarin prior to admission [53].

Interestingly, we found that the study that had the lowest relative risk of stroke associated with $\mathrm{AF}$ also had the greatest reported usage of antiplatelet and/or anticoagulant therapy [21]. The fact that participants in this study had been identified from medical records and, therefore, clinically diagnosed by a GP may also have increased the likelihood of participants being on such therapies. Conversely, the slightly higher relative risk reported by Chien et al. [26] may reflect the lower use of preventive treatment in developing countries [53]. Nevertheless, even when patients are provided with antiplatelet therapy, only about half are treated with the appropriate levels to optimally reduce the risk of stroke $[54,55]$.

We found that strokes related to AF generally accumulate $7-20 \%$ more in direct costs than other strokes, with the majority being due to direct hospital and medical costs. This information is important for obtaining a more accurate estimate of the cost of stroke attributable to AF. For example, the total lifetime costs of AF-related strokes occurring in a single year were estimated in an Australian report to be AUD 215.7 million in 2008-2009 [56]. However, these data are based on the estimated cost per stroke multiplied by the percentage of stroke patients with AF estimated for the whole population. Hence, this is likely to underestimate the true cost of AF-related stroke by $7-20 \%$. This should also be taken into account when the cost-effectiveness of interventions aimed at detecting AF 
and preventing AF-related stroke are assessed. To date, cost-effectiveness analyses relating to anti-thrombolytic medications, and screening and detection programmes have not accounted for this excess cost associated with AF-related stroke [7, 57-59]. Notably, there have been very few studies conducted to estimate the economic impact of AF-related stroke compared with non-AF-related stroke. The quantification of costs related to $\mathrm{AF}$ and stroke is also limited by methodological differences between studies in regards to resource use estimation and the valuation of costs associated with different health care systems. Since relatively little has been published in this area, we were unable to assess any potential changes in the magnitude of cost differentials over time. Further research in this area is needed, as well as assessments of the differentials in stroke severity and whether this is changing with improved preventive treatment and management of stroke.

Finally, there are some limitations that need to be acknowledged. Our strict selection criteria enhanced the accuracy of our comparison of prevalence changes over time but meant that only a small number of studies were included in the review. This would have reduced the sensitivity of our comparisons and meant that only a broad overview of trends in prevalence and stroke risk could be obtained. In general, the small number of articles included in our review is a reflection of the lack of high-quality data available on this topic. Also, to maximise our capture rate for the prevalence studies, we included 2 studies in which participants were screened at baseline using ECG but also identified cases of AF based on medical records. In these studies, slightly inflated prevalence rates were reported. However, this increase was not significant.

A further limitation of our review is that selection of eligible papers was not blinded, and the initial identification of articles for inclusion was performed by one researcher, creating potential selection bias. We attempted to minimise this by using consensus from the three authors for the final selection of papers that were included in the review.

\section{Conclusion}

This literature review provides a contemporary summary of the progress that has been made with regards to $\mathrm{AF}$ in stroke over the last 4 decades. It has further enabled us to identify future public health priorities in this area. First, the age-adjusted prevalence of AF appears not to be changing and may be subject to the competing impacts of advances in the prevention of $\mathrm{AF}$ and improved longterm management of AF, so that those with AF are living for longer. There has also been little change in the overall relative risk of stroke associated with AF. However, in studies with higher levels of anti-thrombotic use, a slightly lower relative risk of stroke associated with AF was reported. Ageing global populations are likely to result in large increases in the total population prevalence of $\mathrm{AF}$ over the next 4 decades. This will place significant health and cost burdens on health systems in both developed and developing nations and will be compounded by the additional excess costs associated with AF-related stroke.

Finally, the large percentage of undiagnosed asymptomatic cases in the community and poor compliance with effective usage and monitoring of medications such as warfarin make stroke prevention particularly challenging. Increased public health efforts are required to identify symptomatic and asymptomatic AF through population screening programmes and to implement strategies to improve prescription of and compliance with taking anticoagulant medications. Improved diagnosis and treatment of AF and its consequences are important for stroke prevention, and renewed efforts in this area are needed if we are to address this growing problem.

\section{Acknowledgments}

Dominique Cadilhac and Amanda Thrift were supported by research fellowships from the National Health and Medical Research Council (grant 610313, co-funded with the National Heart Foundation and 438700). Support funding provided to Dominique Cadilhac by the National Stroke Foundation (PH 09M 4599) and to Nadine Andrew from Monash University, Southern Clinical School, is also acknowledged.

\section{Disclosure Statement}

The authors have no conflicts of interest associated with this research.

References

Neuroepidemiology 2013;40:227-239

Arboix A, Garcia-Eroles L, Massons JB, Oliveres M, Pujades R, Targa C: Atrial fibrillation and stroke: clinical presentation of cardioembolic versus atherothrombotic infarction. Int J Cardiol 2000;73:33-42.

2 Paciaroni M, Agnelli G, Caso V, Venti M, Milia P, Silvestrelli G, Parnetti L, Biagini S: Atrial fibrillation in patients with first-ever stroke: frequency, antithrombotic treatment before the event and effect on clinical outcome. J Thromb Haemost 2005;3:1218-1223. 
3 Lamassa M, Di Carlo A, Pracucci G, Basile AM, Trefoloni G, Vanni P, Spolveri S, Baruffi MC, Landini G, Ghetti A, Wolfe CD, Inzitari D: Characteristics, outcome, and care of stroke associated with atrial fibrillation in Europe: data from a multicenter multinational hospital-based registry (The European Community Stroke Project). Stroke 2001; 32:392-398.

4 Lin HJ, Wolf PA, Kelly-Hayes M, Beiser AS, Kase CS, Benjamin EJ, D'Agostino RB: Stroke severity in atrial fibrillation. The Framingham Study. Stroke 1996;27:17601764.

5 Sandhu RK, Bakal JA, Ezekowitz JA, McAlister FA: The epidemiology of atrial fibrillation in adults depends on locale of diagnosis. Am Heart J 2011;161:986-992.e1.

-6 Biblo L, Yuan Z, Quan K, Mackall J, Rimm A: Risk of stroke in patients with atrial flutter. Am J Cardiol 2001;87:346-349.

7 Hobbs FDR, Fitzmaurice DA, Mant J, Murray E, Jowett $S$, Bryan S, Raftery J, Davies M, Lip G: A randomised controlled trial and cost-effectiveness study of systematic screening (targeted and total population screening) versus routine practice for the detection of atrial fibrillation in people aged 65 and over. The SAFE study. Health Technol Assess 2005; 9:iii-iv, ix-x, 1-74.

8 Wolf PA, Kannel WB, McGee DL, Meeks SL, Bharucha NE, McNamara PM: Duration of atrial fibrillation and imminence of stroke: the Framingham study. Stroke 1983;14:664667.

-9 Savelieva I, Camm AJ: Clinical relevance of silent atrial fibrillation: prevalence, prognosis, quality of life, and management. J Interv Card Electrophysiol 2000;4:369-382.

$\checkmark 10$ Flaker GC, Belew K, Beckman K, Vidaillet H, Kron J, Safford R, Mickel M, Barrell P: Asymptomatic atrial fibrillation: demographic features and prognostic information from the Atrial Fibrillation Follow-up Investigation of Rhythm Management (AFFIRM) study. Am Heart J 2005;149:657-663.

-11 Jabaudon D, Sztajzel J, Sievert K, Landis T, Sztajzel R: Usefulness of ambulatory 7-day ECG monitoring for the detection of atrial fibrillation and flutter after acute stroke and transient ischemic attack. Stroke 2004;35: 1647-1651.

12 Bansil S, Karim H: Detection of atrial fibrillation in patients with acute stroke. J Strok Cerebrovasc Dis 2004;13:12-15.

-13 Parkash R, Wee V, Gardner MJ, Cox JL, Thompson K, Brownell B, Anderson DR: The impact of warfarin use on clinical outcomes in atrial fibrillation: a populationbased study. Can J Cardiol 2007;23:457-461.

- 14 Hart RG, Pearce LA, Aguilar MI: Meta-analysis: antithrombotic therapy to prevent stroke in patients who have nonvalvular atrial fibrillation. Ann Intern Med 2007;146: 857-867.
15 DeWilde S, Carey IM, Emmas C, Richards N, Cook DG: Trends in the prevalence of diagnosed atrial fibrillation, its treatment with anticoagulation and predictors of such treatment in UK primary care. Heart 2006;92: 1064-1070.

16 Benjamin EJ, Chen P-S, Bild DE, Mascette AM, Albert CM, Alonso A, Calkins H, Connolly SJ, Curtis AB, Darbar D, Ellinor PT, Go AS, Goldschlager NF, Heckbert SR, Jalife J, Kerr CR, Levy D, Lloyd-Jones DM, Massie BM, Nattel S, Olgin JE, Packer DL, Po SS, Tsang TSM, Van Wagoner DR, Waldo AL, Wyse DG: Prevention of atrial fibrillation: report from a National Heart, Lung, and Blood Institute workshop. Circulation 2009; 119:606-618.

17 Kristman V, Manno M, Cote P: Loss to follow-up in cohort studies: how much is too much? Eur J Epidemiol 2004;18:751-760.

-18 Sudlow CL, Warlow CP: Comparable studies of the incidence of stroke and its pathological types: results from an international collaboration. International Stroke Incidence Collaboration. Stroke 1997;28:491-499.

19 von Elm E, Altman D, Egger M, Pocock S, Gøtzsche PC, Vandenbroucke JP; STROBE Initiative: The Strengthening the Reporting of Observational Studies in Epidemiology (STROBE) statement: guidelines for reporting observational studies. PLoS Med 2007; 4:e296.

20 Ruo B, Capra AM, Jensvold NG, Go AS: Racial variation in the prevalence of atrial fibrillation among patients with heart failure: the Epidemiology, Practice, Outcomes, and Costs of Heart Failure (EPOCH) study. J Am Coll Cardiol 2004;43:429-435.

21 Rietbrock S, Heeley E, Plumb J, van Staa T: Chronic atrial fibrillation: incidence, prevalence, and prediction of stroke using the Congestive heart failure, Hypertension, Age $>75$, Diabetes mellitus, and prior Stroke or transient ischemic attack (CHADS2) risk stratification scheme. Am Heart J 2008;156: 57-64.

22 Camm AJ, Evans KE, Ward DE, Martin A: The rhythm of the heart in active elderly subjects. Am Heart J 1980;99:598-603.

-23 Lake FR, Cullen KJ, de Klerk NH, McCall MG, Rosman DL: Atrial fibrillation and mortality in an elderly population. Aust NZ J Med 1989;19:321-326.

24 Furberg CD, Psaty BM, Manolio TA, Gardin JM, Smith VE, Rautaharju PM: Prevalence of atrial fibrillation in elderly subjects (the Cardiovascular Health Study). Am J Cardiol 1994;74:236-241.

25 Heeringa J, van der Kuip DAM, Hofman A, Kors JA, van Herpen G, Stricker BHC, Stijnen T, Lip GYH, Witteman JCM: Prevalence, incidence and lifetime risk of atrial fibrillation: the Rotterdam study. Eur Heart J 2006;27:949-953.
26 Chien K-L, Su T-C, Hsu H-C, Chang W-T, Chen P-C, Chen M-F, Lee Y-T: Atrial fibrillation prevalence, incidence and risk of stroke and all-cause death among Chinese. Int J Cardiol 2010;139:173-180.

-27 Bilato C, Corti M-C, Baggio G, Rampazzo D, Cutolo A, Iliceto S, Crepaldi G: Prevalence, functional impact, and mortality of atrial fibrillation in an older Italian population (from the Pro.V.A. study). Am J Cardiol 2009; 104:1092-1097.

-28 de Ruijter W, Westendorp RGJ, Macfarlane PW, Jukema JW, Assendelft WJJ, Gussekloo $\mathrm{J}$ : The routine electrocardiogram for cardiovascular risk stratification in old age: the Leiden 85-plus study. J Am Geriatric Soc 2007;55:872-877.

29 Bonhorst D, Mendes M, Adragao P, De Sousa J, Primo J, Leiria E, Rocha P: Prevalence of atrial fibrillation in the Portuguese population aged 40 and over: the FAMA study. Rev Port Cardiol 2010;29:331-350.

30 Murphy NF, Simpson CR, Jhund PS, Stewart S, Kirkpatrick M, Chalmers J, MacIntyre K, McMurray JJV: A national survey of the prevalence, incidence, primary care burden and treatment of atrial fibrillation in Scotland. Heart 2007;93:606-612.

31 Schmutz M, Beer-Borst S, Meiltz A, Urban P, Gaspoz J-M, Costanza MC, Morabia A, Zimmermann M: Low prevalence of atrial fibrillation in asymptomatic adults in Geneva, Switzerland. Europace 2010;12:475-481.

32 Yap KB, Ng TP, Ong HY: Low prevalence of atrial fibrillation in community-dwelling Chinese aged 55 years or older in Singapore: a population-based study. J Electrocardiol 2008;41:94-98.

33 Iguchi Y, Kimura K, Aoki J, Kobayashi K, Terasawa Y, Sakai K, Shibazaki K: Prevalence of atrial fibrillation in community-dwelling Japanese aged 40 years or older in Japan: analysis of 41,436 non-employee residents in Kurashiki-city. Circ J 2008;72:909-913.

34 Zhou Z, Hu D: An epidemiological study on the prevalence of atrial fibrillation in the Chinese population of mainland China. J Epidemiol 2008;18:209-216.

- 35 Ruigomez A, Garcia Rodriguez LA, Johansson S, Wallander M-A, Edvardsson N: Risk of cerebrovascular accident after a first diagnosis of atrial fibrillation. Clin Cardiol 2007; 30:624-628.

36 Onundarson PT, Thorgeirsson G, Jonmundsson E, Sigfusson N, Hardarson T: Chronic atrial fibrillation - epidemiologic features and 14 year follow-up: a case control study. Eur Heart J 1987;8:521-527.

37 Wolf PA, Abbott RD, Kannel WB: Atrial fibrillation as an independent risk factor for stroke: the Framingham Study. Stroke 1991; 22:983-988. 
38 Friberg J, Scharling H, Gadsboll N, Truelsen T, Jensen GB: Comparison of the impact of atrial fibrillation on the risk of stroke and cardiovascular death in women versus men (The Copenhagen City Heart Study). Am J Cardiol 2004;94:889-894.

- 39 Stewart S, Hart CL, Hole DJ, McMurray JJV: A population-based study of the long-term risks associated with atrial fibrillation: 20 year follow-up of the Renfrew/Paisley study. Am J Med 2002;113:359-364.

40 Simons L, Simons J, Friedlander Y, McCallum J: A comparison of risk factors for coronary heart disease and ischaemic stroke: the Dubbo study of Australian elderly. Heart Lung Circ 2009; 18:330-333.

-41 Bruggenjurgen B, Rossnagel K, Roll S, Andersson FL, Selim D, Muller-Nordhorn J, Nolte CH, Jungehulsing GJ, Villringer A, Willich SN: The impact of atrial fibrillation on the cost of stroke: the Berlin Acute Stroke Study. Value Health 2007;10:137-143.

42 Ghatnekar O, Glader E-L: The effect of atrial fibrillation on stroke-related inpatient costs in Sweden: a 3-year analysis of registry incidence data from 2001. Value Health 2008;11: 862-868.

43 Meretoja A, Kaste M, Roine RO, Juntunen M, Linna M, Hillbom M, Marttila R, Erila T, Rissanen A, Sivenius J, Hakkinen U: Direct costs of patients with stroke can be continuously monitored on a national level: Performance, Effectiveness, and Costs of Treatment episodes in Stroke (PERFECT Stroke) Database in Finland. Stroke 2011;42:20072012.
44 United Nations: World Population Prospects: The 2006 Revision. New York, United Nations Department of Economic and Social Affairs, 2007.

45 Mai Y, Peng X, Chen W: How Fast is Population Ageing in China? Melbourne, Centre of Policy Studies, Monash University, 2009.

46 Kannel WB, Benjamin EJ: Status of the epidemiology of atrial fibrillation. Med Clin North Am 2008;92:17-40.

47 Friberg J, Scharling H, Gadsboll N, Jensen GB: Sex-specific increase in the prevalence of atrial fibrillation. Am J Cardiol 2003;92: 1419-1423.

48 Frost L, Vestergaard P, Mosekilde L, Mortensen LS: Trends in incidence and mortality in the hospital diagnosis of atrial fibrillation or flutter in Denmark, 1980-1999. Int J Cardiol 2005;103:78-84.

49 Wolf PA, Benjamin EJ, Belanger AJ, Kannel WB, Levy D, D’Agostino RB: Secular trends in the prevalence of atrial fibrillation: the Framingham Study. Am Heart J 1996;131: 790-795.

$50 \mathrm{Tu}$ HTH, Campbell BCV, Christensen S, Collins M, De Silva DA, Butcher KS, Parsons MW, Desmond PM, Barber PA, Levi CR, Bladin CF, Donnan GA, Davis SM; Echoplanar Imaging Thrombolytic Evaluation Trial (EPITHET) Investigators: Pathophysiological determinants of worse stroke outcome in atrial fibrillation. Cerebrovasc Dis 2010;30: 389-395.

51 Kannel WB, Wolf PA, Benjamin EJ, Levy D: Prevalence, incidence, prognosis, and predisposing conditions for atrial fibrillation: population-based estimates. Am J Cardiol $1998 ; 82: 2 \mathrm{~N}-9 \mathrm{~N}$.
2 Lip G, Lim H: Atrial fibrillation and stroke prevention. Lancet Neurol 2007;6:981-993.

53 Yu H-C, Tsai Y-F, Chen M-C, Yeh C-H: Underuse of antithrombotic therapy caused high incidence of ischemic stroke in patients with atrial fibrillation. Int J Stroke 2012;7: 112-117.

54 Baker WL, Cios DA, Sander SD, Coleman CI: Meta-analysis to assess the quality of warfarin control in atrial fibrillation patients in the United States. J Manag Care Pharm 2009; 15:244-252.

55 McBride D, Bruggenjurgen B, Roll S, Willich $\mathrm{SN}$ : Anticoagulation treatment for the reduction of stroke in atrial fibrillation: a cohort study to examine the gap between guidelines and routine medical practice. Thromb Thrombolysis 2007;24:65-72.

56 PricewaterhouseCoopers: The Economic Cost of Atrial Fibrillation in Australia, 2010. Prepared for the National Stroke Foundation.

57 Freeman JV, Zhu RP, Owens DK, Garber AM, Hutton DW, Go AS, Wang PJ, Turakhia MP: Cost-effectiveness of dabigatran compared with warfarin for stroke prevention in atrial fibrillation. Ann Intern Med 2011;154: $1-11$.

58 Shah SV, Gage BF: Cost-effectiveness of dabigatran for stroke prophylaxis in atrial fibrillation. Circulation 2011;123:2562-2570.

- 59 Sorensen SV, Kansal AR, Connolly S, Peng S, Linnehan J, Bradley-Kennedy C, Plumb JM: Cost-effectiveness of dabigatran etexilate for the prevention of stroke and systemic embolism in atrial fibrillation: a Canadian payer perspective. Thromb Haemost 2011;105: 908-919. 